\title{
Education and Training of Medical Physicists in Europe.
}

\author{
A.P.Stefanoyiannis ${ }^{*, 1}$, I. Gerogiannis ${ }^{2}$, C. Psichis ${ }^{1}$, X. Geronikola -Trapali ${ }^{1}$, \\ I. Armeniakos ${ }^{1}$, A. Prentakis ${ }^{1}$, P. A. Kaplanis ${ }^{2}$, S. Christofides ${ }^{2}$ \\ ${ }^{1}$ University General Hospital of Athens “Attikon”, Department of Nuclear Medicine, Hellas \\ ${ }^{2}$ Nicosia General Hospital, Medical Physics Department, Cyprus. \\ Received 30 April 2008; Accepted 17 September 2008
}

\begin{abstract}
Introduction: Medical Physicist, as a professional who works in a hospital environment, is a member of a wide clinical team which is responsible for the correct diagnosis and the therapeutic methods applied using radiation. The role of a Medical Physicist is multifold and consists of the estimation of the dose received by patients and personnel, the quality control of radiological equipment, the studies for shielding requirements and the training of several health professionals (doctors, medical physicists, radiologists, technicians, nurses). All the above are prerequisites in order to receive the professional license to act as Medical Physicist.
\end{abstract}

Aim-Research Inquires: The aim of European Union (EU) via European Federation of Medical Physics (EFOMP) is to apply a common policy among the EU countries in the area of Education and Training in Medical Physics within the context of the current developments in the European Higher Education Area arising from "The Bologna Declaration". A short-term perspective is the free movement of professionals within EU, via the assurance of knowledge and skills uniformity. A necessary preliminary stage is the collection, classification and further process of relevant information at the European level.

Methods-Techniques: To achieve the above in an efficient way EFOMP prepared a questionnaire and sent it to the National Organisation for Medical Physics of each country member of EFOMP (NMO). 23 out of 34 country members responded. The main parts ( 3 in total) of this questionnaire and some typical questions were:

Part A: Medical Physics Education

- Which degree is required? Is this a university degree? How many years of studies does it represent?

- Is there a nationally approved education programme and, if yes, then by whom?

- Where do the education and training take place (University, Hospital, or both of them)? Are these centers accredited and who gives the accreditation?

Part B: Qualified / Specialist Medical Physicist

- Is there a license or diploma required to work as Medical Physicist? Is it officially provided (i.e. government)?

Part C: Register of Medical Physicists

- Is there a Register of Medical Physicists in the country? If yes, how is someone registered?

- Is there a renewal mechanism in the Register? If yes, is it based on a Continuing Professional Development system (CPD)?

Results (Summarised):

- In all countries that responded in this questionnaire, the basic educational requirement to enter Medical Physics is a university degree (basic titles: BSc 30\%, MSc 57\%).

- There are 3 different approaches concerning post-graduate education and training (university studies only $23 \%$, hospital only $18 \%$ and combining university and hospital $59 \%$ ).

- In $61 \%$ of all countries it is mandatory to hold a diploma or license to work as a Medical Physicist.

- $65 \%$ of all countries have an organised Register for Medical Physicists.

- A formal CPD programme is in operation in $52 \%$ of the countries.

Conclusions: The processing of the above results leads the EFOMP to propose some general guidelines. It is strongly recommended that holding a university Masters degree (MSc) and having 2 years' training in a hospital environment are the necessary requirements to take the license to act as a Medical Physicist. EFOMP strongly encourages NMO's to organise a formal CPD programme and to include a CPD-based renewal mechanism for the Register of Medical Physicists.

Keywords: medical physics, training, education, guidelines.

\footnotetext{
*E-mail address: apstefano@yahoo.gr

ISSN: 1791-2377 @ 2008 Kavala Institute of Technology. All rights reserved.
} 


\section{Introduction}

The Medical Physicist as a professional who works in a hospital environment is a part of a wide clinical team which is responsible for the correct diagnosis and the application of therapeutic methods using radiation. (EFOMP [5], Eudaldo et al [7]). The role of a Medical Physicist is multifold and consists of the estimation of dose for patients and personnel, the quality control of radiological equipment, the studies for shielding requirements and the training of several health professionals (doctors, medical physicists, radiologists, technicians, nurses). All the above are prerequisites in order to receive the professional license to act as Medical Physicist. Part of the duties-responsibilities of a Medical Physicist and their classification depending on the area of competence that they work are shown in Tab.1 (EFOMP $[5])$.

\section{Aims-Research inquires}

The aim of European Union (EU) via European Federation of Medical Physics (EFOMP) is the existence of a common policy between the EU countries in the area of Education and Training in Medical Physics, within the context of the current developments in the European Higher Education Area arising from "The Bologna Declaration" (Bologna Declaration [1]) and the Directive 2005/36/EC of the EU on the recognition of professional qualifications (Directive [3]). The short-term objectives of the Bologna Declaration are shown in Tab.2. A short-term perspective of Directive 2005/36/EC is the free movement of professionals within EU via the assurance of knowledge and skills uniformity (Schlegel [10]). A necessary initial stage is the collection, classification and further process of relevant information at European level.

Table 1.

Typical responsibilities of Medical Physicist

\begin{tabular}{|c|c|}
\hline $\begin{array}{c}\text { AREA OF } \\
\text { COMPETENCE }\end{array}$ & TYPICAL RESPONSIBILITIES \\
\hline \multirow{5}{*}{ Radiotherapy } & Treatment Planning \\
\hline & Clinical Dosimetry \\
\hline & Quality control of equipment and procedures \\
\hline & Radiation protection of personnel \\
\hline & $\begin{array}{l}\text { Hazard Reports and Quality Assurance- } \\
\text { Control Checks }\end{array}$ \\
\hline \multirow{7}{*}{ Nuclear Medicine } & Estimation of patient's dose. \\
\hline & Quality control of equipment and procedures \\
\hline & Management of radioactive wastes \\
\hline & Radiation protection of personnel \\
\hline & Radiation protection of the environment \\
\hline & $\begin{array}{l}\text { Hazard Reports and Quality Assurance- } \\
\text { Control Checks }\end{array}$ \\
\hline & Optimization of imaging methods \\
\hline \multirow{4}{*}{$\begin{array}{l}\text { Diagnostic } \\
\text { Radiology }\end{array}$} & Quality control of equipment and procedures \\
\hline & Estimation of patient's dose \\
\hline & Optimization of imaging methods \\
\hline & Estimation of fetus' dose in case of pregnancy \\
\hline \multicolumn{2}{|c|}{$\begin{array}{l}\text { Note: In addition and independently of the area of competence the } \\
\text { Medical Physicist is responsible for the training of health } \\
\text { professionals on Radiation Protection issues and also to make } \\
\text { research in several topics of Medical Physics. }\end{array}$} \\
\hline
\end{tabular}

Table 2.

Short-term objectives of the Bologna Declaration

\begin{tabular}{cl}
\hline A/A & \multicolumn{1}{c}{ OBJECTIVES } \\
\hline 1 & Easy recognition and comparison of degrees \\
\hline 2 & $\begin{array}{l}\text { Educational system based on 2 cycles (undergraduate- and } \\
\text { graduate) }\end{array}$ \\
\hline 3 & Educational credits' system (such as ECTS) \\
\hline 4 & Promotion of geographic mobility \\
\hline 5 & $\begin{array}{l}\text { Promotion of geographic co-operation on Quality } \\
\text { Assurance issues }\end{array}$ \\
\hline 6 & $\begin{array}{l}\text { Promotion of the European dimensions in Higher } \\
\text { Education area }\end{array}$ \\
\hline $\begin{array}{l}\text { Bologna Declaration (19-6-1999). At the present phase and after the } \\
\text { Bergen's Conference (19 and 20-5-2005) 45 European countries are } \\
\text { involved. }\end{array}$ \\
\hline
\end{tabular}

\section{Methods-Techniques}

To collect necessary information in an efficient way, a questionnaire was prepared by EFOMP and sent to the National Organisations for Medical Physics of each country member of EFOMP (NMO) for completion. 23 out of 34 country members responded. The main parts ( 3 in total) of this questionnaire and some typical questions are shown in Tab.3 (Christofides [2], Eudaldo and Olsen [8], Eudaldo [9]).

Table 3.

Typical Questions asked to the National Organizations of Medical Physics

\begin{tabular}{|c|c|}
\hline PART & QUESTIONS \\
\hline \multirow{4}{*}{ Medical Physics’ Education } & $\begin{array}{l}\text { Which degree is required? Is this a } \\
\text { university degree? How many years } \\
\text { of studies does it require? }\end{array}$ \\
\hline & $\begin{array}{l}\text { Is there a nationally approved } \\
\text { education programme and, if yes, } \\
\text { then by whom? }\end{array}$ \\
\hline & $\begin{array}{l}\text { Where do the education and training } \\
\text { take place (University, Hospital, or } \\
\text { both of them)? Are these centers } \\
\text { accredited and who gives the } \\
\text { accreditation? }\end{array}$ \\
\hline & $\begin{array}{l}\text { Which is the total duration of the } \\
\text { Education programme and how is the } \\
\text { time education-training distributed? }\end{array}$ \\
\hline \multirow{3}{*}{$\begin{array}{c}\text { Qualified / Specialist } \\
\text { Medical Physicist }\end{array}$} & $\begin{array}{l}\text { Is there a license or diploma required } \\
\text { to work as Medical Physicist? Is it } \\
\text { officially provided (i.e. government)? }\end{array}$ \\
\hline & $\begin{array}{l}\text { Are there alternative ways for } \\
\text { someone to be eligible to work as a } \\
\text { Medical Physicist (except having the } \\
\text { license)? }\end{array}$ \\
\hline & $\begin{array}{l}\text { Is the "diploma" or "license" } \\
\text { equivalent to Qualified Medical } \\
\text { Physicist (QMP) or to Specialist } \\
\text { Medical Physicist (SMP)? }\end{array}$ \\
\hline \multirow{4}{*}{$\begin{array}{c}\text { Register of Medical } \\
\text { Physicists }\end{array}$} & $\begin{array}{l}\text { Is there a Register of Medical } \\
\text { Physicists in the country? If yes, how } \\
\text { is someone registered? }\end{array}$ \\
\hline & $\begin{array}{l}\text { Is the Register entrance voluntary or } \\
\text { compulsory based? }\end{array}$ \\
\hline & $\begin{array}{l}\text { Are there any procedures for Registry } \\
\text { entrance of applicants from a foreign } \\
\text { country, registered on a foreign } \\
\text { approved Register? }\end{array}$ \\
\hline & $\begin{array}{l}\text { Is there a renewal mechanism in the } \\
\text { Register? If yes, is it based on a } \\
\text { Continuing Professional } \\
\text { Development system (CPD)? }\end{array}$ \\
\hline
\end{tabular}




\section{Results}

Summarized:

- In all countries that responded, the basic educational requirement to enter Medical Physics is a university degree (basic titles: BSc 30\%, MSc 57\%).

- The duration of the basic university education ranges from 2 to 5 years.

- There are 3 different approaches concerning post-graduate education and training (university studies only $23 \%$, hospital only $18 \%$ and combining university and hospital $59 \%$ ).

- The total duration of the programme for education and training in Medical Physics ranges from 4.5 to 9 years.

- In $61 \%$ of all countries it is mandatory to hold a diploma or license to work as a Medical Physicist.

- Diploma or license to work as a Medical Physicist allows one to work in all areas of competence (Radiotherapy, Nuclear Medicine, Diagnostic Radiology, Radiation Protection) in $65 \%$ of the countries, whereas in $13 \%$ the area of competence that a Medical Physicist is allowed to work depends on the areas selected during the Education and Training programme.

- $65 \%$ of all countries have an organized Register for Medical Physicists.

- A renewal mechanism exists in $73 \%$ of the Registers.

- A formal CPD programme is in operation in $52 \%$ of the countries.

- $\mathrm{CPD}$ is used as a renewal mechanism in the Register in $100 \%$ of the cases.

\section{Conclusions-Discussion}

EFOMP recognises 2 levels of training for a Medical Physicist working in a hospital environment: the qualified medical physicist (QMP) and the specialised medical physicist (SMP). The QMP has the required training level to work independently and the minimum qualifications required for enrolment in an approved National Register of Medical Physicists by EFOMP. The QMP reaches the level of SMP by gaining substantial clinical experience and participating in the processes of education and training based on an EFOMP's approved National CPD programme.
CPD is an organised reach of knowledge, experiences and skills that required to a Medical Physicist to work at a high quality level during his professional life. EFOMP encourages all Medical Physicists, who have completed the basic education and training, to follow a CPD programme, so that they can maintain or increase their knowledge and skills level after getting the diploma or license to act as Medical Physicists (EFOMP [4], EFOMP [6]).

CPD is considered essential for the employee as well as the employer and generally for the profession trying to ensure the high quality services, as a measure promoting healthy competition or in a court. The advantages for the employee consist of higher professional satisfaction, higher motivation during the work and perspectives for future professional promotion. With the energetic participation into the CPD programme, the employer achieves up-to-date scientific and technologically trained professionals. This will help the natural and successful insertion of new medical practices in the future. Under the processes of CPD, the profession reputation is improved and general recognition is achieved in the benefit of patient and general public, in the case that there is assurance of the conditions for good medical practices (EFOMP [4]).

The implementation of CPD demands the existence of available resources like time, high scientific knowledge and skills level of trainers as well as economic resources (EFOMP [4]). These resources must be offered by those who gain from this process (employee, employer, general public and the corresponding scientific union). Both the employee and the employer contribute money and time so the employee can participate to CPD programmes. The scientific union is responsible for the organisation of such seminars, congresses and other relevant scientific meetings and for the development and management of a formal CPD programme. General public contributes with providing the necessary material and technical infrastructure, as well as the high level trainers.

The processing of the above results leads the EFOMP to the formulation of some general guidelines (Eudaldo and Olsen [8]). Therefore, it is recommended to hold a postgraduate title (MSc) and to have 2 years' training experience in a hospital environment, as essential requirements to achieve the licence or the diploma to work as Medical Physicist. The National Organisations of Medical Physics are strongly encouraged to make a formal CDP programme and have a renewal mechanism in the Register of Medical Physicists and a promotion from QMP to SMP, both based on CDP programme.

\section{References}

1. Bologna Declaration, http://bologna-bergen2005.no, (1999).

2. S. Christofides, "EFOMP new initiatives and activities" First European Conference on Medical Physics, Pisa, Italy, Book of Abstracts, p. 4, (2007).

3. Directive 2005/36/EC of the European Parliament and of the Council of 7 September 2005 on the recognition of professional qualifications, Official Journal of the European Communities No. L 255, 30.9.2005; p. 22-142, (2005).

4. EFOMP Policy Statement No. 8, "Continuing Professional Development for the Medical Physicist" Physica Medica, XIV, p. 81-83, (1998).

5. EFOMP Policy Statement No. 9, "Radiation Protection of the Patient in Europe: The Training of the Medical Physics Expert in
Radiation Physics or Radiation Technology". Physica Medica , XV, p. 149-153, (1999)

6. EFOMP Policy Statement No. 10, "Recommended Guidelines on National Schemes for Continuing Professional Development of Medical Physicists" Physica Medica, XVII, p. 97-101, (2001).

7. T. Eudaldo, H. Huizenga, I.-L. Lamm, A. McKenzie, F. Milano, W. Schlegel, D. Thwaites, G. Heeren, "Guidelines for education and training of medical physicists in radiotherapy: recommendations from an ESTRO/EFOMP working group" Radiotherapy and Oncology, 70, p.125-135, (2004).

8. T. Eudaldo, K. Olsen, "The present status of Medical Physics Education and Training in Europe. New perspectives and EFOMP recommendations", http://www.efomp.org/policy/ETP_report1.pdf, (2007a). 
9. T. Eudaldo, "The present status of Medical Physics Education and Training in Europe: an EFOMP survey" First European Conference on Medical Physics, Pisa, Italy, Book of Abstracts, p. 3, (2007b).
10. W. Schlegel, "Future goals of EFOMP in Education, Profession and Science" First European Conference on Medical Physics, Pisa, Italy, Book of Abstracts, p. 3, (2007). 